\title{
A ONTOLOGIA DA OPERATIVIDADE NA OBRA DE GIORGIO AGAMBEN
}

\author{
THE ONTOLOGY OF OPERABILITY IN THE WORKS OF GIORGIO AGAMBEN
}

\author{
DANIEL ARRUDA NASCIMENTO ${ }^{1}$ \\ Universidade Federal Fluminense (UFF) - Brasil \\ danielarrudanascimento@id.uff.br
}

\begin{abstract}
RESUMO: Revistando o livro Opus Dei: archeologia dell'ufficio de Giorgio Agamben, publicado em 2012, pretendo nas páginas que se seguem expor em nova luz a crítica da ontologia da operatividade e da efetividade proposta pelo filósofo italiano. Se em Il regno e la gloria: per una genealogia teologica dell'economia e del governo, publicado em 2007, se tratava de investigar a inoperosidade divina e humana como elemento constitutivo da nossa cultura governamental, cabe agora introduzir os disparadores que permitirão a crítica à operatividade. Como veremos, o seu pensamento está assim alinhado a uma fileira de críticos da ontologia que inclui autores de diferentes matizes, todos incomodados com que se poderia chamar de alienação ontológica. Considero que, na sua acepção contemporânea, essa linha se estende de Søren Kierkegaard a Hannah Arendt, passando evidentemente por Martin Heidegger. Ao final, veremos como o reconhecimento do triunfo do agir e do fazer sobre o âmbito do ser, do triunfo do ato sobre a potência, influi sobre a política contemporânea. L'uso dei corpi, publicado em 2014, nos auxiliará nesse caminho.
\end{abstract}

PALAVRAS-CHAVE: Filosofia política. Giorgio Agamben. Ontologia da operatividade.

ABSTRACT: Reading again the book Opus Dei: archeologia dell'ufficio written by Giorgio Agamben, published in 2012, we present, through a proper light, his critical assessment of the ontology of operability and of the ontology of effectiveness. If in Il regno e la gloria: per una genealogia teologica dell'economia e del governo, published in 2007, the focus was to investigate the divine and human inoperability as a constitutive element of our governmental culture, at this point the aim is to introduce the triggers that will allow the criticism of operability. As we will see, his philosophy is thereby adjusted to a line of ontological thinkers which include authors from different backgrounds, all of them concerned with what could be called ontological alienation. In a contemporary aception, this line is extended from Søren Kierkegaard to Hannah Arendt, passing through Martin Heidegger: At the end of the article, we will examine how the acknowledgment of the triumph of acting and making against the sphere of being, the triumph of act against potency, influence contemporary politics. L'uso dei corpi, published in 2014, will help us in this last moment

KEYWORDS: Political philosophy. Giorgio Agamben. Ontology of operability.

\footnotetext{
${ }^{1}$ Professor do Instituto de Ciências da Sociedade da Universidade Federal Fluminense (UFF) e do Programa de Pós-Graduação em Filosofia da Universidade Federal do Espírito Santo (UFES).
} 
O novo livro de Giorgio Agamben que se pergunta sobre o conceito de filosofia, no qual figura a propósito o título Che cos'è la filosofia?, coloca-nos diante de uma afirmação que se explica com maior largueza apenas se confrontada com a ontologia da operatividade apresentada antes em Opus Dei: archeologia dell'ufficio. A afirmação que viceja no capítulo Sul concetto di esigenza, um capítulo curto no qual a mútua implicação entre os conceitos de filosofia e exigência é reafirmada, é a seguinte: "a exigência é uma categoria da ontologia e não da moral" (AGAMBEN, 2016, p. 51). A exigência pertence ao âmbito do estudo do ser e não pode ser confundida com um acessório do âmbito moral, a exigir este ou aquele comportamento humano em sociedade, como a indicação de uma necessidade de conformação, a acusação de uma carência ou reclamação daquilo que é devido. A exigência é uma categoria da ontologia. Consequentemente, "do fato que a exigência não seja uma categoria moral, resulta que dela não pode advir nenhum imperativo, que ela não tenha nada a ver com um dever-ser", ao mesmo tempo em que nenhuma presença factual seja adequada para explicitá-la, a exigência "não pode nunca ser posta sobre o plano da realização", que a exigência seja "o estado de complicação extrema de um ser, que compreende em si todas as suas possibilidades" (AGAMBEN, 2016, p. 52-55). Já em Il tempo che resta: un commento alla Lettera ai Romani, o autor havia defendido expressamente que a exigência designa uma relação entre o ser e a sua possibilidade, que não precede mas segue a realidade. Alterando o sentido de uma sentença clássica, ele acrescentaria que "omne existens exigit possibilitatem suam, todo existente exige a própria possibilidade, exige de se tornar possível" (AGAMBEN, 2000, p. 43). ${ }^{2}$

Estamos acostumados a aceitar que as exigências que nos fazem sejam arraigadas ao terreno ético, ou melhor, moral, isto é, que espelhem demandas por comportamentos convenientes para as diversas situações apresentadas ao agente e para os diversos papéis sociais que sustentamos no nosso cotidiano em sociedade. De onde vem essa nossa percepção? Certamente do fato de estarmos desde muito cedo sujeitos ao julgamento alheio e percebermos que os nossos ganhos e as nossas perdas dependem dos resultados desses julgamentos. Sabemos assim que as nossas pretensões somente serão satisfeitas se nos adequarmos aos padrões exigidos no meio no qual queremos obtê-las. A variação do meio determina a variação das exigências, está claro. Aprendemos que determinados comportamentos são valorizados e outros são desprezados nos ambientes que escolhemos frequentar, que há muitas vezes modelos a serem seguidos e, em última análise, que somente atingiremos um bom resultado na satisfação dos nossos desejos se nos assemelharmos a estes modelos. Isto vale inclusive para os ambientes que procuram se apresentar como ambientes alternativos aos espaços difusos da moralidade dominante: embora se apresentem como alternativas críticas, eles adotam com uma frequência maior do que gostariam de admitir a mesma postura. As exigências estão então na ordem do dia e as recebemos como pertencentes ao terreno moral, ao terreno da administração dos comportamentos, dos comportamentos que aparecem no meio social. Se o ambiente é piedoso ou

\footnotetext{
${ }^{2}$ Em um diálogo prolongado com Gottfried Leibniz, a questão do conceito de exigência será ainda retomada em L'uso dei corpi (cf. p. 218-221).
} 
tem apelo assistencial, importa fazer caridade e não ser caridoso. As exigências podem ser mais fortes inclusive no estado de indigência moral em que nos movemos, no qual se ainda existem no nível do discurso balizamentos morais para as ações humanas, as virtudes que são valorizadas no senso comum são aquelas que nos orientam para um determinado resultado: ser socialmente bem sucedido, obter sucesso. Nesse aspecto, não há dúvidas do que entendemos por sucesso: no mundo em que nos movemos, ter sucesso é ter dinheiro e prestígio. O poder, compreendido aqui de maneira trivial como a capacidade de uma pessoa ou de um grupo de pessoas, é apenas um meio eficaz para se conseguir dinheiro e prestígio (cobrando também um alto preço àqueles que o detém). A felicidade do consumo e a sociedade do espetáculo possuem esses dois motores.

Em Opus Dei, Giorgio Agamben havia demonstrado que a difusão e a permanência do termo ofício nos textos eclesiásticos, filosóficos e jurídicos produziram uma transformação na ontologia, que passa a adotar como paradigma a operatividade e a efetualidade, a ação produtiva e eficaz. ${ }^{3}$ Isto porque officium, a palavra que traduzira para a língua latina o grego leitougia na tradição teológica cristã, porta desde a sua aparição definitiva uma tensão, expressa com lucidez na teoria sacramental: a palavra está tensionada pela tentativa de compatibilização entre a ação soteriológica divina e a colaboração humana na administração dos sacramentos. A questão seria como compatibilizar a perfeição divina na sua ação que salva o homem destinatário da administração dos sacramentos com a imperfeição humana manifestada nas mais variadas maneiras, no seu estado de pouca fé, na sua condição de estar em pecado, no cometimento de erros formais na execução do ato, na negligência em relação aos necessários zelo e devoção. Como sendo imperfeito poderia o homem contribuir para salvação divina? A solução encontrada, elaborada ao longo dos primeiros séculos cristãos, foi considerar que a simples realização de um ato pelo ministro confere o fluxo da ação salvífica divina, independentemente das condições acidentais de sua realização, presentes os elementos mínimos para a sua realização. Cumprido o rito com a observância de algumas regras mínimas, acessíveis e materialmente verificáveis, o sacramento tem o seu efeito desejado. Os sacramentos funcionam ex opere operato, tendo como destino doutrinário a consagração do primado do efeito. Interessa ao ofício, sobretudo, a obtenção de resultados, tornar presente alguma realização por meio de um agir e de um fazer. Isto significa que a ontologia sofre aí uma notória modificação, "implica uma transformação da ontologia, na qual substancialidade e eficácia parecem se identificar" (AGAMBEN, 2013, p. 50). Nas palavras do filósofo italiano:

[...] enquanto no vocabulário da ontologia clássica o ser e a substância são considerados independentemente dos efeitos que possam produzir, na efetualidade o ser é inseparável de seus efeitos, ela denomina o ser na medida em que é efetual, produz certos efeitos e, ao mesmo tempo, é determinado por eles. A efetualidade é, portanto, a nova

\footnotetext{
${ }^{3}$ Paradigma que hoje se insere também na dinâmica da crise, ou das crises, entre tantas outras anunciadas pelo filósofo ao longo de seu percurso editorial, inclusive nos momentos que antecedem aos intensos anos de produção na filosofia política a partir de 1995. Com a imagem da crise termina a introdução de Opus Dei (cf. AGAMBEN, 2013, p. 08-09).
} 
dimensão ontológica que se afirma primeiro em âmbito litúrgico para depois estender-se progressivamente até coincidir na modernidade com o ser enquanto tal (AGAMBEN, 2013, p. 51).

Mede-se aqui com clareza a mutação do paradigma ontológico que é já um fato completo: o ser coincide sem resíduos com a efetualidade, no sentido em que não é simplesmente, mas deve ser efetuado e realizado. Decisiva não é tanto a opera como estável demora na presença, mas a operatividade, entendida como um limiar no qual ser e agir, potência e ato [...] entram em tensão recíproca e tendem a se tornar indecidíveis (AGAMBEN, 2013, p. 56, grifos do original).

Do interior desta nova ontologia, uma ontologia da operatividade e da efetualidade, que provoca um deslocamento do ser para a esfera da praxe, devemos compreender que o ser é aquilo que faz e enquanto faz algo determinado pela efetualidade. Como disse em outra ocasião, "o ser coincide com o fazer, effectus indica um modo de ser em que o ser é aquilo que faz, dito de outra forma, uma modalidade de ser que somente é enquanto age ou que deve agir para poder ser" (NASCIMENTO, 2014, p. 112). Mais que de uma redução à praxe e à realização de tarefas, a denunciada mutação na ontologia significa uma inversão na medida em que o ser deve agora se subordinar ao agir e ao fazer, o ser é apenas na medida em que se apresenta no mundo fenomênico enquanto obra. A partir de então, será a obra que definirá o ser, passamos a considerar a qualidade do ser pela qualidade da sua manifestação. Se em Il regno e la gloria: per una genealogia teologica dell'economia e del governo, publicado alguns anos antes, se tratava de investigar a hipótese da inoperosidade divina e humana como elemento constitutivo da nossa cultura governamental, capturada ambiguamente em nossa máquina econômicogovernamental (e, em alguma medida, de procurar restituir a política à sua dimensão inoperosa própria, acrescenta as premícias do livro), cabe agora introduzir os disparadores que permitirão a crítica à operatividade. Como apreendemos do prefácio de Opus Dei, olhamos o problema por dois ângulos distintos e complementares. A pesquisa arqueológica deste último volume, gêmeo do primeiro, através da interrogação da prática litúrgica na sua administração terrena, põe em relevo a ontologia da operatividade, para preparar o caminho para as análises conclusivas de L'uso dei corpi.

O trabalho de Agamben expresso especialmente em Opus Dei, mas não apenas nesse volume, como veremos, é uma denúncia da ontologia moderna, do triunfo do agir e do fazer sobre o âmbito do ser, do triunfo do ato sobre a potência. ${ }^{4}$ O seu pensamento está assim alinhado a uma fileira de críticos da ontologia que inclui autores de diferentes matizes, todos incomodados com que se poderia chamar de alienação ontológica. Do que melhor se pode esperar da filosofia, o

\footnotetext{
${ }^{4}$ Por não interessar de modo estrito ao propósito da presente análise, deixamos de lado aqui a alusão à segunda transformação ontológica que dá corpo ao livro Opus Dei, a ontologia do comando, que depois da ontologia da operatividade e da efetualidade, enceta os capítulos três e quatro da obra. Uma breve apresentação da ontologia do comando no conjunto da obra pode ser encontrada em Anotações para a leitura de Opus Dei (cf. NASCIMENTO, 2013, p. 109-124).
} 
filósofo se associa a filósofos que vieram antes dele e que caminharam pela mesma vereda. Considero que, na sua acepção contemporânea, essa linha se estende de Søren Kierkegaard a Hannah Arendt, passando evidentemente por Martin Heidegger. A leitura desses três autores, bem conhecidos do filósofo italiano, permite observar como o incômodo não é recente. Cada um deles, a seu modo, soube colocar em relevo a crítica da alienação ontológica e expor suas consequências no mundo atual. Acompanhemos uma pequena excursão na companhia desses autores.

Após longos anos de pseudonímia, Søren Kierkegaard publica em nome próprio As obras do amor: algumas considerações cristãs em forma de discursos. Tão caros lhes eram os temas ali abordados, tratados com tamanha honestidade e lucidez, que por si só justificariam desta vez o emprego do próprio nome. É provável que o autor compreendesse ser devida ainda uma contribuição sua dessa envergadura, depois de uma juventude prolongada em que o não esteve sempre presente em sua vida, com a recusa inclusive de se tornar pastor luterano, mesmo tendo estudado para isso. Dois capítulos do livro nos interessam particularmente. Em ambos, está em jogo a discussão sobre a possibilidade de o amor produzir obras e de ser reconhecido por estas obras produzidas, tendo como mote introdutório o comentário à passagem bíblica do capítulo seis do Evangelho de Lucas, versículo quarenta e quatro: "cada árvore se reconhece pelo fruto que lhe é próprio; não se colhem figos de um espinheiro, nem se colhem uvas de sarças". Se o recado óbvio do versículo é que uma árvore deve produzir frutos para ser reconhecida, tudo levaria a crer que estaríamos diante de um discurso elogioso das obras, das manifestações do amor. Não é esta a conclusão a que nos leva o autor. O apreço demonstrado pelas obras não é maior que o elogio do próprio amor, que mora em lugar oculto, segundo Kierkegaard. O amor pode produzir obras, mas as obras não asseguram que exista amor. Assim como os frutos podem enganar, não se pode ter plena confiança nos frutos (cf. KIERKEGAARD, 2005, pp. 27-29). Uma atitude humana pode parecer amor quando é amor próprio, amor de si, expressão do desejo de ser amado pelo espetáculo do amor que se produz, pela aparência que se sustenta em sociedade. Assim pode ser, por exemplo, uma atitude de socorro para quem está na miséria. Gestos de distribuição de renda e de auxílio a quem está em uma situação de carência são na maioria das vezes produzidos no apelo de uma propaganda de si. Ou para o alívio da alma culpada que sabe, no fundo, que o mérito e o merecimento são nomes dados muitas vezes a privilégios da loteria da vida social ou a culminâncias de processos de exploração. Cabe notar que, no tempo político em que escrevo estas páginas, militâncias que sustentam o discurso do mais amor são muitas vezes militâncias meramente performáticas. Para o filósofo dinamarquês, igualmente, um fruto ruim ou insuficiente poder ser também um indício de que o amor seja farsa, de que não se trata de amor: "a imaturidade e o falso amor se reconhecem pelo fato de que as palavras e os modos de falar são seu único fruto" (KIERKEGAARD, 2005, p. 27). As palavras são exterioridades fracas do amor, acompanhadas muitas vezes da dissimulação ou mesmo temperadas pelo discurso de ódio. 
O fato de não podermos confiar plenamente nas obras para se reconhecer se existe amor esvazia de conteúdo simbólico a frase bíblica pelos frutos se conhece a árvore. As árvores boas não podem deixar de dar bons frutos por que isto é da sua natureza, mas os bons frutos não atestam que a árvore seja boa, que existe amor. Na reflexão desenvolvida por Kierkegaard, o amor pertence a uma realidade interior, não factual, não operativa ou efetual. As obras são produzidas como um epifenômeno. Mas o reconhecimento do amor é contingente, enquanto o que importa é que o próprio amor exista, o que nos coloca diante de uma realidade ontológica. Diz-se que o amor tem necessidade de ser conhecido pela obra assim como se diz que o amante tem necessidade de sentir o seu amor pelo amado (cf. KIERKEGAARD, 2005, p. 22-25). A rigor, não se trata de uma necessidade, mas de uma riqueza, um transbordamento e um deleite. Se o amor pertence a uma vida oculta, nem por isso ele esconde as suas exterioridades. $\mathrm{O}$ amor pode aparecer, é mesmo uma consequência natural que ele apareça, embora isto não seja necessário e o amor permaneça em uma realidade inacessível. Nenhum humano está autorizado assim a conhecer com toda certeza se há amor, a julgar o quanto de amor esconde cada gesto ou obra. O filósofo dinamarquês enfatiza que é preciso crer no amor que não se dá a conhecer e que crer no amor é uma felicidade (cf. KIERKEGAARD, 2005, p. 30-31). Encorajado, é bastante provável, por uma antiga intuição cristã que procura inspirar a confiança de que quem acredita no amor e procura amar vive melhor.

Contudo, será o discurso sobre a misericórdia nas Obras do amor que dará uma palavra definitiva sobre a questão. A misericórdia é uma obra do amor e não depende da ação exterior. "A misericórdia, uma obra do amor, mesmo quando ele não tem nada para dar e nem tem condições de fazer nada" (KIERKEGAARD, 2005, p. 357). A misericórdia é uma obra do amor mesmo quando inoperosa e inefetiva, a sua investigação demonstra que ser deve ter o primado sobre o ter, o dar, o fazer, o agir: "Poder ser misericordioso é uma perfeição muito maior do que possuir dinheiro e consequentemente poder dá-lo [...] podemos ser misericordiosos mesmo quando não podemos fazer nem o mínimo" (KIERKEGAARD, 2005, pp. 357 e 365 , grifos do original). O valor e o resultado efetivo de uma ação misericordiosa são acessórios, pouco relevantes diante da dimensão existencial: uma ação pode ser misericordiosa e expressar o amor mesmo que nada opere na realidade fenomênica, mesmo que o seu resultado seja um fracasso. Cuida-se de um estranho cálculo, longe da contabilidade da generosidade. "Oh! Deixa que os redatores dos periódicos, os coletores do fisco e os reis dos mendigos falem da generosidade e das contas e mais contas", nas palavras irônicas do filósofo dinamarquês (KIERKEGAARD, 2005, p. 355). Quem ama, não sabe calcular. Quem procura reconhecer o amor pelas obras, também não. Por isso, o filósofo ainda brinca no mesmo capítulo com o fato de que a misericórdia não pode ser retratada em imagens, nenhum pintor leva a sério a hipótese de criar uma pintura que tenha como objeto a misericórdia, na medida em que os atos exteriores a serem aportados para a tela sempre diriam muito pouco. Um naufrágio pode ser pintado, os perigos do mar podem ser retratados, mas os gestos de misericórdia serão sempre ambíguos e sujeitos à dúvida perspicaz. 
Incontornável é, nesse contexto da alienação ontológica, a sonora presença de Martin Heidegger. Leitor de Kierkegaard e professor de Agamben, a sua influência sobre este último foi muitas vezes enfatizada pelo seu aluno, não apenas pela sua frequente menção nos textos do filósofo italiano, mas por indicações expressas sempre que oportuno em suas declarações sobre a sua trajetória acadêmica e sobre o cabedal de influências. ${ }^{5}$ Em Opus Dei não poderia ser de outro modo. Cabe observar que nesse momento Agamben atribui a Heidegger o gesto de encontrar as razões para a transformação da ontologia moderna no argumento teológico criacionista, bem como na passagem substitutiva da energeia para actualitas, em consulta ao capítulo $A$ metafísica como história do ser de seu Nietzsche, o que poderia expressar a demarcação de diferenças entre o seu pensamento e o do filósofo alemão. Da clássica distinção aristotélica entre potência e ato, dynamis e energeia, o ser teria sido afastado da essência originária da energeia para tornar-se actualitas, opus. Para Agamben, todavia, a hipótese tem consistência e pode ser compreendida em conjunto com a proposta que traz em Opus Dei, embora no caminho da crítica à história do esquecimento do ser e da retomada da questão do sentido do ser, a eleição do Dasein como ponto de partida possa ainda significar que a ontologia de Heidegger seja mais solidária do que se crê com o paradigma da operatividade que pretende distanciar, uma vez que o incessante projetar-se para o ser mais próprio pode ser compreendido também como uma tarefa, ou seja, designar algo eminentemente efetual (cf. AGAMBEN, 2013, p. 67-70). Não obstante, Ser e tempo é fundamental para se aquilatar como é contundente a crítica do filósofo alemão à ontologia da operatividade.

Do interior da analítica existencial promovida por Martin Heidegger, o serno-mundo é condição necessária e prioritária do Dasein, embora insuficiente por si só para determinar a sua plenitude ontológica, informa o importante parágrafo doze de Ser e tempo. Como constituição fundamental do Dasein, deste ente que nós mesmos somos (parágrafo nove), deste ente que se nunca exclui uma variedade multiforme de características ontológicas constitutivas, igualmente originárias do ponto de vista existencial (consoante mais adiante salientará o parágrafo vinte e oito), o fenômeno do ser-no-mundo explica em que condições o Dasein se apresenta e se move no seu mundo. Nada de espacial, é claro, tratase de condição existencial. Também não se cuida de uma disputa entre o espiritual e o mundano, como se os diversos modos de ser-no-mundo pudessem não existir. Desde o início e essencialmente, o ser-em possui o modo de ser da ocupação, que onticamente pode ser compreendido como o fazer algo, "ter que fazer alguma coisa, produzir alguma coisa, [...] empreender, [...] realizar alguma coisa, cumprir, 'levar a cabo"' (HEIDEGGER, 2015, p. 103). Esta é uma possibilidade, como é uma possibilidade a compreensão da ocupação como um modo de engajamento ontológico no mundo. De qualquer modo, para a analítica existencial e a fenomenologia, o Dasein não pode escapar desta condição de ocupar-se. Assim como não pode escapar da condição de que a sua ocupação seja dada com base

\footnotetext{
${ }^{5}$ Com os ares de uma autobiografia, uma palavra definitiva sobre o assunto foi dada por Giorgio Agamben em Autoritratto nello studio, publicado em 2017, livro escrito em primeira pessoa e envolto a uma profusão de fotografias, no qual se pode concluir que a relevância de Martin Heidegger na vida intelectual do autor é manifesta.
} 
na familiaridade do mundo, ou seja, com base nas relações com todo ente intramundano que lhe vem ao encontro, como todo instrumento que está ao seu alcance (cf. HEIDEGGER, 2015, p. 125). Na condição de estar lançado em um mundo, o mundo se apresenta para o Dasein como um mundo que exige a realização de tarefas que possam ser relatadas numérica e qualitativamente.

O capítulo mais ácido de Ser e tempo, porém, traz no seu prólogo a seguinte questão: "quais são os caracteres existenciais da abertura do ser-no-mundo quando o ser-no-mundo cotidiano se detém no modo de ser do impessoal?" (HEIDEGGER, 2015, p. 230). O impessoal já havia sido definido no parágrafo vinte e sete como a adoção do modo de ser dos outros, pelo fenômeno do nivelamento social, retirando-se a responsabilidade pelo que se é. Agora o filósofo alemão denomina de decadência a leitura fenomenológica que propõe. Ao lado do falatório e da ambiguidade, está a curiosidade retratada no parágrafo trinta e seis como fenômeno determinante da cotidianidade do Dasein, aquele que mais nos interessa nas presentes páginas. Em um mundo onde os olhos têm a primazia, onde o sentido da visão orienta os demais sentidos humanos, "o ser-no-mundo está, numa primeira aproximação, empenhado no mundo das ocupações” (HEIDEGGER, 2015, p. 236). A ocupação aparece assim comprometida com o mundo do trabalho e com as providências a serem tomadas no expediente diário. É bom notar, com a intenção de se expor a ontologia da operatividade, que Martin Heidegger se utiliza no parágrafo de evidências que traduzem a demanda por um fazer. Mais do que isto, por realizações que exprimem, no caso, a impermanência. Não se pode deixar de fazer as coisas, quanto mais melhor, quanto mais novo melhor: exigência de realizar, impermanência em relação ao que está próximo, dispersão contínua na busca por novidades, desamparo por não encontrar descanso ou fidelidade ao que se é. Por isso, especialmente em um mundo do trabalho hoje universalmente inserido nas modulações do mercado capitalista, subordinado aos princípios da livre iniciativa e concorrência, quem trabalha lança-se em muitos projetos sem terminá-los, ou relata-se muito do já feito sem que os feitos impliquem realizações sólidas. Embora o filósofo de Ser e tempo não abra fogo direto contra a assim chamada ontologia da operatividade, ela está explicitamente presente em passagens no texto que ressentem o esquecimento do ser.

Alguém poderia objetar que mais de vinte e cinco anos depois Heidegger define como produção a relação do homem com a técnica e a criação do mundo. Isto o colocaria na mira da operatividade? Não creio, tendo em vista a tonalidade filosófica adotada no período. A técnica é costumeiramente entendida como um meio para consecução um fim e uma atividade humana, a produção de utensílios e instrumentos, máquinas e indústrias, mas não é esta a concepção que interessa ao filósofo no novo fôlego que orienta os seus escritos na década de cinquenta. A técnica que o cativa é a técnica que é uma forma de desencobrimento, que permite a passagem do encoberto para o descoberto, da produção de algo que traduz um deixar-viger: Cuida-se então de uma regência que antecede à ação do homem, primordial em relação ao esforço humano (cf. HEIDEGGER, 2001, p. 15-25). Ainda que a técnica moderna operada pelo homem, que tem a sua essência no que o autor dá o nome de Gestell, queira ter o controle da natureza, o trabalho do 
homem é responder respeitosamente ao que se desencobre, é colocar-se no caminho do desencobrimento, proteger e guardar o que o apela (cf. HEIDEGGER, 2001, p. 15-25). A questão da técnica, conferência proferida nos anos em que já não importava mais estar tão presente à universidade, situa o seu autor mais uma vez à margem do paradigma da operatividade. O homem produz em sintonia ou dissintonia com o que se manifesta sem dependência, o que significa que o agir e o fazer humanos não estão no centro da criação permanente do mundo. $O$ desencobrimento nunca é simplesmente um feito do homem, ao produzir o homem corresponde a um apelo do desencobrimento. Cito uma passagem conclusiva: "de novo, se impõe a pergunta: será que este desencobrir-se se dá, em algum lugar, fora de toda ação e qualquer atividade humana? De forma alguma! Mas também não acontece apenas no homem e nem decisivamente pelo homem" (HEIDEGGER, 2001, p. 26-27, grifos do original). O maior perigo para o nosso mundo, e em termos muito concretos, o que o expõe ao risco da destruição ambiental sem precedentes que desafortunadamente assistimos em escala global, é que o homem entenda que tudo o que lhe vem ao encontro no mundo fenomênico "só existe à medida que é um feito do homem" (HEIDEGGER, 2001, p. 29). Colocando a coisa desta maneira, dificilmente poderia se afirmar que o filósofo alemão está retido na ontologia da operatividade. Ao final da arqueologia do reino e do governo levada a cabo por Agamben em Il regno e la gloria, um parágrafo sobre o pensamento de Heidegger aponta que a Gestell adquire um novo significado se concebida como o dispositivo do absoluto e integral governo do mundo, embora com a ressalva de que o filósofo da floresta negra não chega a arrematar o problema da técnica porque não o restitui ao seu locus político (cf. AGAMBEN, 2007, p. 275-276).

Hannah Arendt, leitora de Kierkegaard e Heidegger, fonte de inspiração para Agamben, tem também um passo importante na experimentação crítica da ontologia da operatividade. No livro que tem como tema o que estamos fazendo e as origens da alienação do mundo moderno, segundo o prólogo escrito pela própria autora, encontramos nova abordagem do problema. A condição humana se inicia com a advertência de dois eventos decisivos para o mundo contemporâneo, a tentativa de libertação do trabalho que é realizado pelo homem em virtude do advento da automação, por um lado, e a aparentemente contraditória glorificação teórica do trabalho, no qual todos os homens são nivelados pelo trabalho como atividade principal e meio para o ganho do próprio sustento, por outro lado, recordando-se que mais à frente o trabalho será definido como aquilo que produz um mundo artificial de objetos (cf. ARENDT, 2004, pp. 12-15). Mas estamos ainda longe do sentido da ontologia da operatividade desenvolvido pela pensadora alemã se nos fixarmos apenas no mundo do trabalho. Para designar a condição humana, mormente no que se assinala com a expressão vita activa, Hannah Arendt se propõe a vasculhar os meandros das atividades do labor, do trabalho e da ação nas transformações que tiveram lugar na modernidade. A crítica da ontologia da operatividade não está justamente na exclusão da ação e da contemplação no mundo moderno, nas substituições pelo homo faber e pelo animal laborans, pela fabricação de objetos úteis para a permanência do mundo e 
pela ocupação nas atividades que garantem a satisfação das necessidades do corpo e da vida? Vejamos o que nesse sentido se pode dizer em relação à ação.

A convicção de que o máximo que o homem pode atingir é o aparecimento e a realização de si mesmo não é, de modo algum, natural e corriqueira. Contra ela há a convicção do homo faber de que os produtos feitos pelo homem podem vir a ser mais - e não apenas mais duradouros - que o próprio homem, como há também a firme crença do animal laborans de que a vida é o bem supremo. A rigor, ambos são, portanto, apolíticos e tenderão a denunciar a ação e o discurso como ociosidade - intrometimento ocioso ou conversa ociosa (ARENDT, 2004, p. 220).

A partir de um momento histórico não seguramente determinável a ação passa a denotar outra coisa que não a espontaneidade humana na vida política, há uma clara e incessante tentativa de se expropriar a ação de todo conteúdo político, de retirá-la do âmbito dos negócios humanos e da organização do convívio na cidade. Mesmo "a expressão vita activa perdeu o seu significado especificamente político e passou a denotar todo tipo de engajamento ativo nas coisas deste mundo" (ARENDT, 2004, p. 22), todo ato decorrente do movimento do corpo humano em meio a coisas e pessoas. Especialmente, substitui-se a ação pela fabricação, a idade moderna interpreta a ação como uma modalidade de fabricação, em termos de instrumentalidade, de produção de ferramentas úteis para o trabalho do homem. Difundindo-se a preocupação com a produção e acumulação de bens, com a garantia da ordem e do progresso, a modernidade procura evitar a política, no seu exaspero contra as três características malditas da ação: a imprevisibilidade dos seus resultados, a irreversibilidade dos processos uma vez desencadeados e o anonimato dos autores historicamente relevantes (cf. ARENDT, 2004, p. 232-234). A ação deve, portanto, ser operativa e efetual, deve ter algum resultado palpável que se possa mostrar ao final do processo, tomandose como modelo a fabricação de objetos. Nesse sentido cabe observar que, se outrora a felicidade humana estava na participação na vida pública da cidade e na administração das decisões que a conduziriam a um futuro comum, agora ela se restringe às alegrias da vida privada confortável. Ademais, a suspeita que um estado de coisas como esse levanta em relação à democracia é notada por Arendt. Poderíamos acrescentar que a criação de uma democracia que se reduz ao sistema de representação política pode ser também um modo de neutralizar a ação. A defesa da representação política por Benjamin Constant no clássico Da liberdade dos antigos comparada à dos modernos, discurso pronunciado no coração de Paris em 1819, o testemunha. À liberdade dos modernos satisfaz o abandono da política aos profissionais de política na representação, para que possam livremente agir e atuar em relação aos negócios privados, empreender. Nas palavras de Benjamin Constant, "a independência individual é a primeira das necessidades modernas [...] não se deve nunca pedir seu sacrifício para estabelecer a liberdade política [...] nenhuma das numerosas instituições, tão aplaudidas, que, nas repúblicas antigas, 
impediam a liberdade individual é aceitável nos tempos modernos". 6 A nós modernos compete a vida de empresários e fabricantes, mesmo sem qualquer empresa para gerir que não seja a própria força de trabalho.

Ao lado do investimento contra a ação, Hannah Arendt colocará a inversão da ordem hierárquica entre a vita contemplativa e a vita activa, "talvez como a mais grave consequência espiritual das descobertas da era moderna" (ARENDT, 2004, p. 302). Não apenas a inversão entre vida ativa e vida contemplativa e a definitiva abolição da contemplação na vida moderna, mas especialmente a assunção da contemplação como serva da ação já modulada, como etapa fugaz de um processo de fabricação. Pensar e contemplar são atividades diferentes de agir e fazer, com muito custo podem ser chamadas de atividades. Estão agora a serviço do fazer e do fabricar, da produtividade e de seu apetite por sempre mais, o que de acordo com a pensadora alemã, explica uma das causas da filosofia ter perdido espaço entre os homens na modernidade. Se quiserem, depois dos anos de publicação da Condição humana, em que o lançamento de um satélite artificial à órbita terrestre representava o evento tecnológico mais notório, as tecnologias de informação e as redes sociais submetem o pensar a um regime de concorrência tão veloz quanto o seu desaparecimento na irrelevância. ${ }^{7}$ Antes da vitória derradeira do animal laborans no nosso tempo, o ontologia da operatividade deixou a sua marca: "em lugar do conceito de ser, encontramos agora o conceito de processo", do processo de fabricação de objetos. Pior, encontramos um desvirtuado conceito de fabricação, "afastando-se da questão de o que uma coisa é e de que tipo de coisa deve ser produzida para a questão de como e através de que meios e processos ela veio a existir e pode ser reproduzida". Nesse sentido, "a moderna troca de ênfase do o que para o como, da coisa para o processo de sua fabricação, não foi de modo algum um bem isento de males" (ARENDT, 2004, p. 309-310, 317 e 320, respectivamente). O pensamento que não produzir objetos úteis não tem valor. A única contemplação que permanece é a do engenheiro e a do operador de máquinas, ou seja, tem como mira o objeto ideal que será criado pelo processo de produção para posterior destinação ao comércio.

Do ponto de vista de Hannah Arendt, tudo isto não ocorre sem influir sobre a política, sobre a capacidade dos homens negociarem entre si em um ambiente de pluralidade e construírem um futuro comum. A partir da instalação teórica definitiva de que os homens estão em igualdade de condições, o racionalismo

\footnotetext{
${ }^{6}$ A citação está na página 10 da versão consultada. Antes da passagem, o autor dá a tônica do discurso ao enfatizar que o mundo moderno mudou a vida humana. "O comércio não deixa, como a guerra, intervalos de inatividade na vida do homem. O exercício contínuo dos direitos políticos, a discussão diária dos negócios de Estado, as discussões, os conciliábulos, todo o cortejo e movimento das facções, agitações necessárias, recheio indispensável, se ouso empregar esta expressão, na vida dos povos livres da antiguidade, que se teriam entediado, sem esse recurso, sob o peso de uma ociosidade dolorosa, acarretariam apenas perturbação e cansaço às nações modernas, onde cada indivíduo, ocupado por suas especulações, por seus empreendimentos, pelos resultados que obtém ou espera, quer ser desviado disso o menos possível" (p. 05).

${ }^{7}$ A pergunta que inaugura a página de todo perfil do Facebook, no que você está pensando, é um acinte ao tempo do pensamento e ao seu retiro necessário. Os poucos amigos que levam a sério esta pergunta devem se submeter sem defesa à sua dinâmica frívola e destinada ao desaparecimento. Com maior prejuízo: ao fato de se exporem em uma vitrine em constante disputa, à mercantilização das relações humanas e ter que escutar a intervenção de gente que escreve sem pensar.
} 
moderno e a visão mecanicista de mundo já haviam assimilado que a única política possível seria aquela viabilizada pela criação de um homem artificial, um corpo estatal que funcionasse tão bem quanto um relógio. O século dezessete vê surgir então tentativas de introduzir o paradigma da operatividade na esfera da política. Fugindo ao assim concebido estado de natureza, o Estado Moderno criado na dinâmica da fabricação oferece a solução caseira para a produção e o governo do mundo político, o que equivale à construção de uma máquina, um mecanismo que opera pela interação das suas partes entre si (cf. ARENDT, 2004, p. 312-313). Mais adiante, a vitoriosa eleição da vida como bem supremo e a também vitoriosa concepção cristã da imortalidade da alma humana, não importa o que o homem faça sobre a terra (concepção que sobreviveria à secularização e ao arrefecimento da fé cristã, visceralmente adjuntas ao século dezenove), foram desastrosas para a política, uma vez que retirou do homem a responsabilidade pelo seu mundo, fazendo da política a gerência das necessidades humanas básicas. Basta ao homem trabalhar para ganhar o seu pão, se necessário for, isto é, se alguma prosperidade alheia não the tiver por sorte beneficiado. ${ }^{8}$ Por uma razão diametralmente oposta, a valorização da vida tem como resultado a alienação extraterrena do mundo (cf. ARENDT, 2004, p. 327-329). Não resta, assim sendo, dignidade para a política e para a ação: "a ação logo passou a ser, e ainda é, concebida em termos de fazer e de fabricar, exceto que o fazer, dada a sua mundanidade e inerente indiferença à vida, era agora visto como apenas outra forma de labor, como função mais complicada mas não mais vitoriosa do processo vital" (ARENDT, 2004, p. 335). A ação, que fulgurava outrora ao lado do discurso enquanto atividade humana privilegiada na política, tornando a política possível, sofre um duro golpe, ou melhor, dois golpes, primeiro pela sua interpretação como fazer, depois pela sua anulação como labutar para o sustento da vida.

Como vemos, especialmente em Arendt, mas não apenas nela, política e ontologia não estão apartados, tal como poderia a princípio parecer. A discussão que ocupa estas linhas nos leva de volta a L'uso dei corpi, o último volume do projeto filosófico-político de Giorgio Agamben, maturado durante vinte anos, onde se lê que "ontologia e política se correspondem perfeitamente" ou, em uma versão mais abrangente, "política e ontologia, dispositivos ontológicos e dispositivos políticos são solidários, porque precisam um do outro para se realizar" (AGAMBEN, 2014, p. 173 e 176). Cabe perquirir de que modo a ontologia da operatividade e da efetividade influi sobre a política. Em outras palavras, como o reconhecimento do triunfo do agir e do fazer sobre o âmbito do ser, do triunfo do ato sobre a potência, influi sobre a política contemporânea. Finalizando um projeto filosófico de trajetória inusitada, que havia iniciado sob o horizonte biopolítico em Homo sacer: il potere sovrano e la nuda vita (com o reconhecimento de que a política contemporânea teria sem reservas se tornado biopolítica), no contexto em que problemáticas são as cisões da vida humana, o autor salientará que "uma desativação da máquina biopolítica implica necessariamente uma desativação do

\footnotetext{
${ }^{8}$ De acordo com Arendt, a filosofia cristã mais recente teria desmerecido o trabalho como virtude ou reparação do pecado original, o que, a meu ver, não é uma observação isenta de problemas, especialmente se levarmos em conta que a palavra trabalho é polissêmica e pode designar tanto a prestação de serviço à comunidade quanto uma realidade intelectual ou espiritual.
} 
dispositivo ontológico (e vice-versa)" (AGAMBEN, 2014, p. 261). Opus Dei e L'uso dei corpi são definitivamente também livros políticos.

Entre os anos 1996 e 2004, o tema em pauta já estava parcialmente desenvolvido por Agamben (no artigo L'opera dell'uomo, mas também na conferência Heidegger e il nazismo). Valendo-se mais uma vez de uma ponderação aristotélica, em La potenza del pensiero: saggi e conferenze já está manifesta a noção de que há uma inoperosidade essencial no homem, a hipótese de que o homem seja no seu ambiente profundo argos, sem obra, e de que a política corresponda à inoperosidade essencial do homem (cf. AGAMBEN, 2005, pp. 338 e 372-384). Ora, se a política é a inoperosidade, como entender uma política que foi determinada pela ontologia da operatividade e da efetividade, uma política qualificada pelas obras e resultados? Ainda pode ser chamada de política? Colocar em questão a centralidade do agir e do fazer na política é uma das intenções confessadas de L'uso dei corpi. Se no início da terceira parte do livro o conceitochave de forma-de-vida, que viria a se tornar tão relevante no projeto filosófico, designa antes de tudo uma potência, um ser de potência, ao final acrescenta-se que dá-se forma-de-vida somente onde há contemplação de uma potência, retorno à inoperosidade, restituição à possibilidade (cf. AGAMBEN, 2014, p. 264-265 e 313). Nesse sentido, política denomina o se tornar humano do homem. A vida propriamente humana é a vida política. Isto é afirmar que é na política que o homem encontra a sua humanidade, se torna mais humano. Igualmente, que política não pode ser compreendida apenas na sua redução mais comum: um universo institucional separado do mundo comum dos homens, um campo minado sitiado por profissionais de terno e gravata, um mercado de trabalho especializado para gente empoderada. Ao lado dessa inconteste redução, vemos esse mundo adulterado cobrir de louros as obras que revelariam um agir e um fazer. Por isso, considera-se a melhor política a política monumental. Deixar monumentos é fundamental nesse mundo, alterado duplamente pela sociedade espetacularizada, na qual é necessário antes de tudo mostrar algo, mesmo que não se tenha nada para mostrar. Publicidade, propaganda, marketing, são eles que sugam os recursos de qualquer gestão pública nos dias de hoje, assim como dos empreendimentos individuais de personalidade.

Com a publicação de L'uso dei corpi, o filósofo italiano tem um objetivo em mente: contribuir para a desativação e suspensão das obras da economia, do direito, da biologia e assim por diante. É deste modo que ele o verbaliza em entrevista ao jornal alemão Die Zeit, poucos meses depois da publicação do livro. A Europa precisa colapsar e apenas uma forma especial de atividade que seja uma inoperosidade pode desobstruir o caminho para uma política que vem, mas que ainda não chegou..$^{9}$ O que não será realizado, evidentemente, por um livro. Mas seus leitores, talvez, tenham a habilidade de convocar essa inoperosidade e invocar a política. É preciso estancar a ontologia da operatividade. Resta saber se a sua

9 A Europa precisa colapsar é o título da entrevista que responde a uma polêmica que envolveu o autor dois anos antes e que ficou conhecida como a polêmica do império latino, em alusão crítica à constituição meramente econômica da União Europeia e às posturas mais enérgicas do governo alemão no período. Sobre a explicação dos seus objetivos com a publicação de L'uso dei corpi, conferir as páginas 08 e 09 da tradução consultada. 
obra expandida vem em nosso auxílio, se os conceitos alistados por ele podem nos guiar no resgate da dignidade da política, ou melhor, no retorno da política ao seu lugar próprio. Na linguagem do filósofo, na invenção da política que vem (inventar é a palavra usada pelo autor na introdução do primeiro volume da série, Homo sacer: il potere sovrano e la nuda vita). O pensamento experimentado como potência antagonista à ontologia que se impõe como operatividade, tão inerente à atual fase do sistema capitalista de produção e consumo, e a forma-de-vida que lhe corresponde, enquanto vida inseparável de sua forma e oposição ao domínio da vida nua, devem se tornar os conceitos guias da política que vem (cf. AGAMBEN, 2014, p. 271-272). Penso que as provocativas intuições de Agamben têm algo a nos dizer, ainda que não digam tudo, como não poderia deixar de ser. Dividindo um destino comum com a política, a ontologia do nosso tempo está exposta à ingerência da operatividade e da efetividade. Quer se trate de invenção de algo novo, quer se trate da liberação de algo que aguarda alguma redenção, compete a nós habitantes do século vinte e um dar ouvidos.

\section{REFERÊNCIAS BIBLIOGRÁFICAS}

AGAMBEN, Giorgio. Autoritratto nello studio. Milano: Nottetempo, 2017.

. Che cos'è la filosofia? Macerata: Quodlibet, 2016.

. L’uso dei corpi. Vicenza: Neri Pozza, 2014.

Opus Dei: arqueologia do ofício. Tradução de Daniel Arruda Nascimento. São Paulo: Boitempo, 2013.

Il regno e la gloria: per una genealogia teologica dell'economia e del governo. Vicenza: Neri Pozza, 2007.

. La potenza del pensiero: saggi e conferenze. Vicenza: Neri Pozza, 2005.

. Il tempo che resta: un commento alla Lettera ai Romani. Torino: Bollati

Bolinghieri, 2000.

Homo sacer: il potere sovrano e la nuda vita. Torino: Piccola Biblioteca Einaudi, 1995.

A Europa precisa colapsar: entrevista com Giorgio Agamben, por Iris Radisch (Die Zeit), Revista Profanações, ano 3, no 1 , tradução Marcelo Hanser Saraiva, revisão Oswaldo Giacoia Junior, p. 238-248, jan./jun. 2016.

ARENDT, Hannah. A condição humana. Tradução de Roberto Raposo. Rio de Janeiro: Forense Universitária, 2004.

CONSTANT, Benjamin. Da liberdade dos antigos comparada à dos modernos. Disponivel em: <http://Www.fafich.ufmg.br/ luarnaut/Constant_liberdade.pdf $>$. Acesso em: 10/11/2014.

HEIDEGGER, Martin. Ser e tempo. Tradução revisada de Márcia Sá Cavalcante Schuback. 10ª edição. Petrópolis: Vozes, 2015. 
HEIDEGGER, Martin. Ensaios e conferências. Tradução de Emmanuel Carneiro Leão, Gilvan Fogel e Márcia Sá Cavalcante Schuback. Petrópolis: Vozes, 2001.

KIERKEGAARD, Søren. A. As obras do amor: algumas considerações cristãs em forma de discursos. Tradução de Álvaro L. M. Valls. Petrópolis: Vozes, 2005.

NASCIMENTO, Daniel A. Umbrais de Giorgio Agamben: para onde nos conduz o homo sacer? São Paulo: LiberArs, 2014.

Ipseidade e alteridade em Heidegger e Kierkegaard. 2007. 107 f. Dissertação (Mestrado em Filosofia) - Departamento de Filosofia, Pontifícia Universidade Católica do Rio de Janeiro, Rio de Janeiro, 2007. 